\title{
Characterization of Peanut Shells for Their Valorization in Earth Brick
}

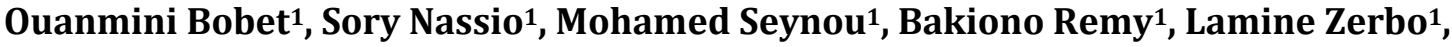 \\ Issiaka Sanou ${ }^{2}$, Moustapha Sawadogo' ${ }^{1}$ Younoussa Millogo ${ }^{2}$, Escadeillas Gilles ${ }^{3}$ \\ ${ }^{1}$ University Joseph KI-ZERBO, UFR-SEA, Ouagadougou, Burkina Faso \\ ${ }^{2}$ University Nazi BONI, UFR-ST, Bobo-Dioulasso, Burkina Faso \\ ${ }^{3}$ Laboratoire Matériaux et Durabilité des Constructions (LMDC), Université de Toulouse, UPS, INSA, Toulouse, France \\ Email: sanoussiaka@yahoo.fr
}

How to cite this paper: Bobet, O., Nassio, S., Seynou, M., Remy, B., Zerbo, L., Sanou, I., Sawadogo, M., Millogo, Y. and Gilles, E. (2020) Characterization of Peanut Shells for Their Valorization in Earth Brick. Journal of Minerals and Materials Characterization and Engineering, 8, 301-315.

https://doi.org/10.4236/jmmce.2020.84018

Received: June 15, 2020

Accepted: July 27, 2020

Published: July 30, 2020

Copyright $\odot 2020$ by author(s) and Scientific Research Publishing Inc. This work is licensed under the Creative Commons Attribution International License (CC BY 4.0).

http://creativecommons.org/licenses/by/4.0/

\begin{abstract}
Peanut shells from Burkina Faso were characterized using mineralogical, microstructural and chemical methods to perform its possibility to be used as reinforce in adobe bricks. It consists of cellulose (48 wt\%), hemicellulose (3 $\mathrm{wt} \%)$ and lignin (28 wt\%). The peanut shells were characterized by high porosity and showed water absorption around $198 \%$ at 72 hours. Its chemical composition is essentially composed of silica, iron oxides, alumina and calcium oxide. Its microstructure showed that the peanut shells were a compilation of microfibers with high porous of borders. In watery solution, the peanut shells released polyphenols. Thermal conductivity of peanut at $25^{\circ} \mathrm{C}$ was $0.155 \pm 0.021 \mathrm{~W} / \mathrm{mK}$. The physico-chemical characteristics of peanut shells were similar to those found with agricultural by-products used in adobe reinforce.
\end{abstract}

\section{Keywords}

Agricultural Wastes, Peanut Shells, Thermal Conductivity, Adobes, Durability

\section{Introduction}

Agricultural by-products were widely used as additives in earth bricks production [1] [2] [3]. As a fiber of plant or the wastes of products, they were used in earth brick to improve its durability [1] [2] [3] [4]. Agricultural by-products in earth brick increase dimensional stability, reduce the cracking of bricks, enhance its mechanical properties and improve its resistance to rain erosion [5] [6]. At the same time, as improving durability of bricks, the use of agricultural by-product reduces its thermal conductivity which allows it to have habitats offering thermal comfort. 
One of agricultural by-products abundant in Burkina Faso was the peanut shell (PS). Agro-residue of peanut, the shells were mostly abandoned in crop field without a very important issue of valorization. The annual production of peanut in Burkina Faso alone approximatively 334,000 tons [7]. The quantity of shell provides by the peanut corresponds to third part of this annual production.

Many researchers have investigated the use of peanut shells as a carbon source for crop fertilization, as a substrate to remove some impurities of polluted water, as a source of oligosaccharides and as a potential antioxidant and antimicrobial [8] [9]. However, results about peanut shells and their use as reinforce on earth building materials were not available. Many results were available on the use of a large number of fibers (kenaf, fonio, sisal, flax, hemp, bamboo) and wastes (straw, coconut) as reinforce of adobe [2]. Conclusions about mechanisms involved in the enhancement of properties linked to the use of agricultural by-products were sometimes conflicting. The results are closely related to chemistry (cellulose, hemicellulose, lignin, pectin), microstructure (porosity, stiffness) and particle size distribution (filler properties) of the used agricultural by-product. So, the organic compound released by agricultural waste in watery solution participates in the mechanisms.

This paper is devoted to analyzing of peanut shells for their physico-chemical, mineralogical, microstructural and thermal conductivity properties to evaluate its suitability as a reinforce of adobe.

\section{Raw Materials and Experimental Methods}

\subsection{Raw Materials}

The agricultural waste subject of this work is the peanut shell from Laye, village at $35 \mathrm{~km}$ north of Ouagadougou. It is a by-product of a leguminous plant (Figure 1) called peanut with botanically named Arachis Hypogaea L. Peanut belongs to the subfamily of Papilionaceae in the Fabaceae family. Flowering plant with height around 20 to $90 \mathrm{~cm}$, peanut is grown in warm areas due to its resistance to heat and drought. Peanut is farm mainly for its seeds and oil. It is the sixth largest source of oil production in the world (FAO 2003). Peanut shells were used by local population in the construction of their traditional habitat. The shells were sometimes used in crushed form or powder form to amend adobes.

\subsection{Experimental Methods}

\subsubsection{Characterization of Unground Peanut Shells}

\section{1) Microstructure of peanut shells}

Microstructure of peanut shells was observed by scanning electron microscopy using a JEOL $6380 \mathrm{LV}$ equipped with a backscattered electron (BSE) detector. Direct observations were made using SEM in low-vacuum (LV) mode (no metallization necessary, with a pressure of $60 \mathrm{~Pa}$ in the SEM chamber).

The elemental quantitative analyses were performed by the energy dispersive spectrometry (EDS) technique using a Brüker X Flash 6/30 detector. 

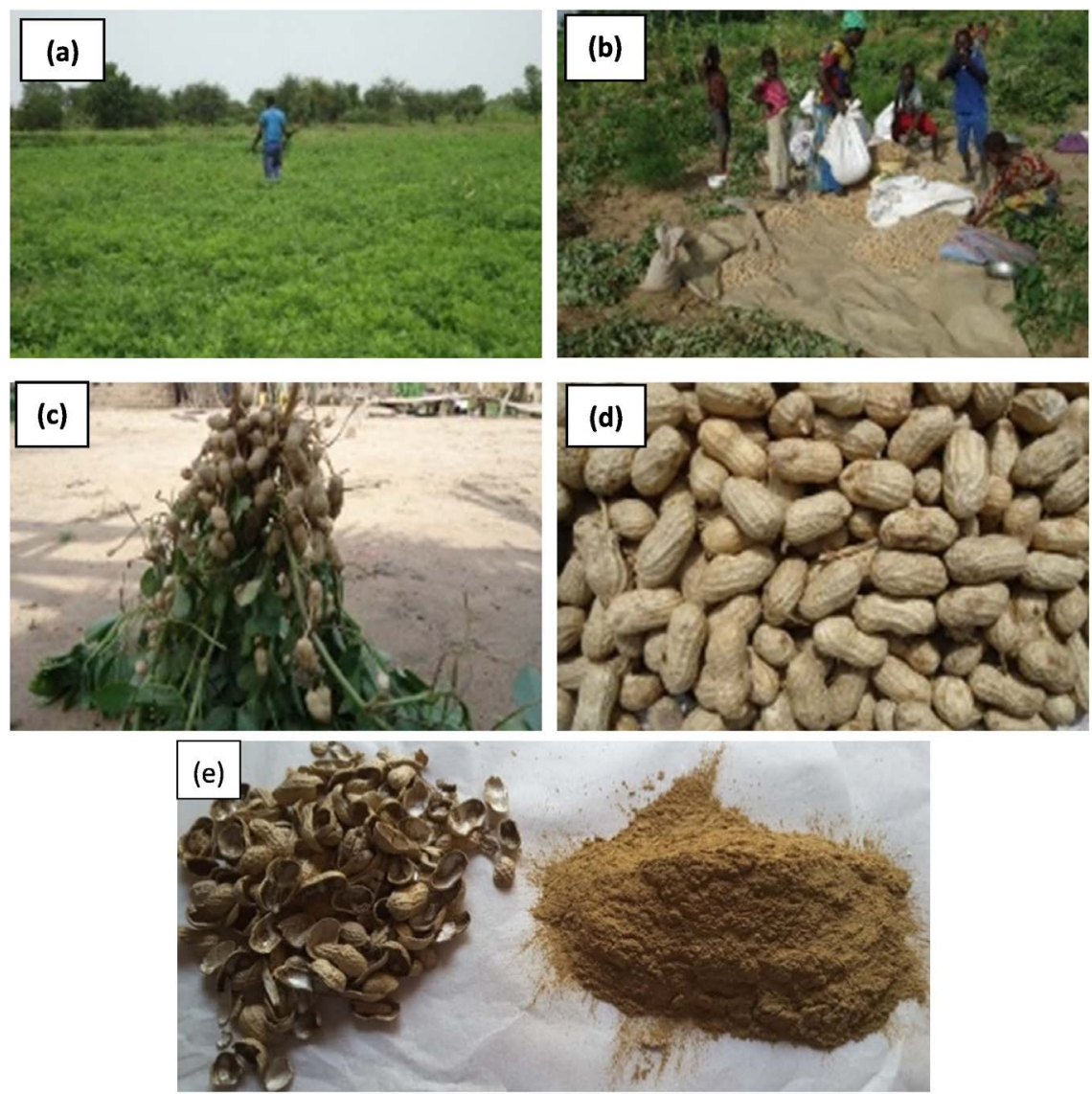

Figure 1. Images of peanut plants, (a) peanut fields; (b) peanut harvest; (c) peanut plant; (d) peanut; (e) peanut shells and its powder.

\section{2) Water absorption of peanut shells}

Water absorption of peanut shells was performed according to the method described by Juarez [10] and renew by Magniont [11] for the fibers. The shells were dried an oven at $105^{\circ} \mathrm{C}$ until the stabilize mass. Six (06) samples of approximately $1 \mathrm{~g}$ were tested each time. They were immersed in distilled water for 5, 15, 30 minutes, 24, 48 and 72 hours. At the end of each immersion period, the shells were superficially dried using absorbent paper to remove the internal water on the surface. The weighing was carried out using $10^{-2} \mathrm{~g}$ precise scale. Water absorption of the shells is determined by the relation 1 .

$$
A(\%)=\frac{M_{2}-M_{1}}{M_{1}} \times 100
$$

With:

- $M_{1}$ : dry mass of shells (g);

- $M_{2}$ : saturated mass of shells after immersion (g).

\subsubsection{Characterization of Peanut Shells Powder}

\section{1) Physico-chimical analyze}

The density of peanut shell powder $(\Phi<80 \mu \mathrm{m})$ was measured by hydrostatic weighing using garosolve D70 as the immersion liquid. The moisture content 
and the loss on ignition of peanut shell powder are evaluated with a Nabertherm $\mathrm{C} 250$ oven at $105^{\circ} \mathrm{C}$ for 24 hours and $1000^{\circ} \mathrm{C}$ for 2 hours, respectively.

The particle size distribution of peanut shells powder $(\Phi<80 \mu \mathrm{m})$ was performed with laser diffraction using CILAS 1090 Liquide apparatus.

Elementary chemical analysis of peanut shells was performed with X-ray Fluorescence wavelength dispersive technique with a Bruker TIGER S8.

\section{2) Mineralogical analyze}

The mineralogical composition of peanut shell powders was carried out by coupling X-ray diffraction, infrared spectrometry, differential scanning calorimetry and thermogravimetric analysis. X-ray diffraction was carried out with a Brüker D8 Advance apparatus equipped with a monochromator and using Ka radiation $(\lambda=1.54 \AA)$ of copper. Infrared spectrometry was recorded with a Perkin Elmer UATR 1 Frontier FI-IR apparatus in the range of 550 to $4000 \mathrm{~cm}^{-1}$ wavenumber. Differential scanning calorimetry and thermogravimetric analysis were performed with a Netzsch SATA $449 \mathrm{~F} 3$ device up to $1000^{\circ} \mathrm{C}$ with $10^{\circ} \mathrm{C} / \mathrm{min}$ as the heating rate.

The quantities of cellulose, hemicellulose and lignin were recorded according to the following protocol. $40 \mathrm{~g}$ of peanut shells (previously pulverized) were mixed with $800 \mathrm{ml}$ of $2 \mathrm{M} \mathrm{KOH}$, and the whole was heated at $80^{\circ} \mathrm{C}$ under stirring for 5 hours. The residue was filtered, washed with a solution of acetic acid $5 \%$ and after with distilled water until neutralization. The obtained residue called "enrichment cellulose (EC)" was dried at ambient temperature (for 5 days) until an invariable mass. The mass ratio of the residue obtained by the initial mass corresponds to the content of cellulose, lignin and hemicellulose. To determine cellulose content, $2 \mathrm{~g}$ of EC were treated with a mixture of $50 \mathrm{~mL}$ of $0.17 \mathrm{M} \mathrm{K}_{2} \mathrm{Cr}_{2} \mathrm{O}_{7}$ and $25 \mathrm{~mL}$ of $20 \% \mathrm{H}_{2} \mathrm{SO}_{4}$. The whole is stirred for 2 hours, filtered and washed extensively with distilled water. The residue is dried at ambient temperature until an invariable mass is obtained. The ratio of the mass obtained after drying with the $2 \mathrm{~g}$ of EC corresponds to the cellulose content.

To determine lignin content, $2 \mathrm{~g}(\mathrm{M})$ of EC were mixed with $30 \mathrm{ml}$ of $72 \%$ $\mathrm{H}_{2} \mathrm{SO}_{4}$. The whole is stirred for 2 hours, after diluted 7 times (with $10 \%$ sulfuric acid) and the mixture is then heated under reflux in a water bath for 3 hours. The mixture was filtered and the precipitate was collected and washed extensively with distilled water to neutralize and dry at $110^{\circ} \mathrm{C}$ for 20 hours. The mass of obtained product represents the mass $\mathrm{P}_{1}$. The calcined residue at $500^{\circ} \mathrm{C}$ for 5 hours and weighed corresponds to mineral salts mass $\mathrm{P}_{2}$. The residual lignin (RL) is calculated according to relation 2 .

$$
R L(\%)=\frac{P_{1}-P_{2}}{M} \times 100
$$

With, $P_{1}, P_{2}$ and $M$ in g.

\section{3) Analyze of extract from peanut shells}

The extract of peanut shells was analyzed using UV-visible spectrometry. The extraction was done using two ways. For the first way, the peanut shells were 
crushed and sun dried. For the second way, the peanut shells were dried in the shade and crushed afterwards. In each of the used way, $1 \mathrm{~g}$ of crushed shells is introduced successively into a tube containing $6 \mathrm{ml}$ of distilled water taken at room temperature and a second tube containing $12 \mathrm{ml}$ of a solution of solvent ( 0.5 $\mathrm{v} / \mathrm{v}$ acetic acid; $5 \mathrm{v} / \mathrm{v}$ and acetone $70 \mathrm{v} / \mathrm{v})$. The decoction is collected after 48 hours.

Total polyphenolic content of peanut shells extracts was evaluated using Folin-Ciocalteu reagent and gallic acid according to method described by Singleton et al. [12]. The absorbance value was taken at $760 \mathrm{~nm}$ CIBA-CORNING $2800 \mathrm{Spec}-$ trascan UV spectrometer. Gallic acid was used as a standard to plot the calibrate curve. The total polyphenolic content of the peanut shell extract was expressed as microgram gallic acid equivalent per gram of shell.

\section{4) Thermal conductivity of peanut shells}

Thermal conductivity $(\lambda)$ of the shells was measured using a KD2 Pro analyzer. For this purpose, prismatic $4 \times 4 \times 16 \mathrm{~cm}^{3}$ bricks were molded from the paste obtained by mixing peanut shells powder with water. The specimens were demolded after 24 hours and dried in ambient air for three days before being baked for 2 hours at $40^{\circ} \mathrm{C}$ (Figure 2). TR-1 probe (diameter $2.4 \mathrm{~mm}$, length $100 \mathrm{~mm}$, operating over the range of 0.1 to $4 \mathrm{~W} \cdot \mathrm{m}^{-1} \cdot \mathrm{K}^{-1}$ ) is introduced into a hole in the center of one of the square faces of the specimen so that there is no contact with air.

\section{5) Capillary absorption of peanut shells-based brick}

Capillary water absorption is an important parameter to discussed about the porosity and the durability of elaborated material. Prismatic $4 \times 4 \times 16 \mathrm{~cm}^{3}$ bricks were molded from the paste obtained by mixing peanut shells powder with water. The specimens were demolded after 24 hours and dried in ambient air for three days before being baked for 2 hours at $40^{\circ} \mathrm{C}$. The specimen water absorption by capillarity was evaluated according to standards NF EN 1015-18. Capillary absorption was calculated using Equation (3):

$$
\frac{Q}{A}=S \sqrt{t}
$$

where $Q$ is the amount of water absorbed $(\mathrm{kg})$ by the specimen, $A$ is the surface $\left(\mathrm{m}^{2}\right)$ of specimen in contact with water, $t$ is the contact time $(\mathrm{s})$ and $\mathrm{S}$ the sorptivity coefficient of specimen $\left(\mathrm{kg} \cdot \mathrm{m}^{-2} \cdot \mathrm{s}^{-1 / 2}\right)$.

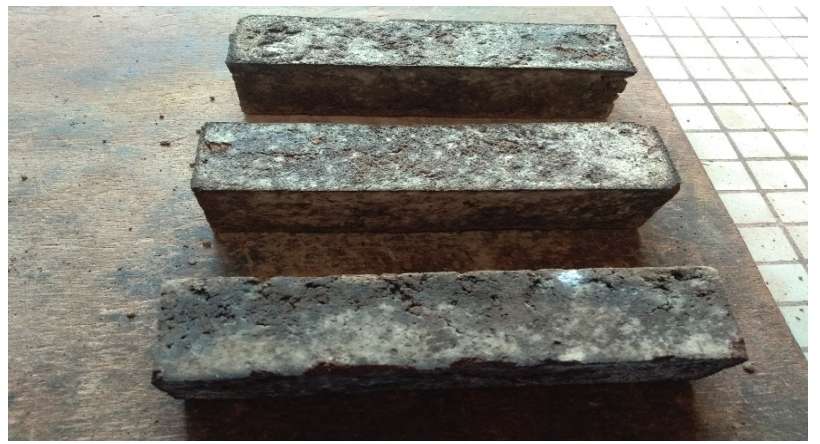

Figure 2. Specimens of peanut shell powder used to measure thermal conductivity. 


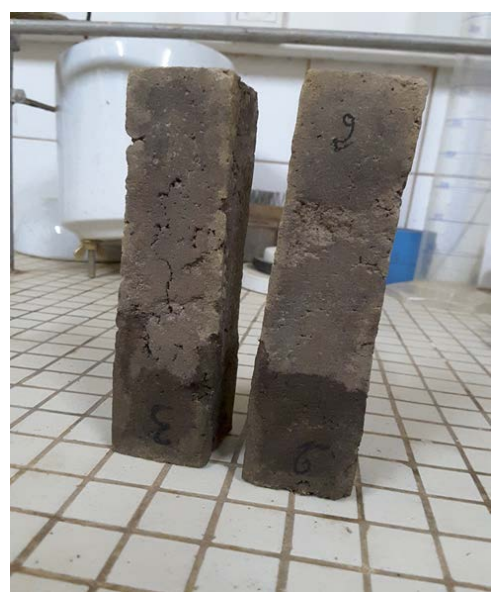

Figure 3. Specimen after the capillary absorption test.

\section{Results}

\subsection{Microstructure of Unground Shells}

Microstructure examination is important to predict roughness and porosity of the shells. SEM images of peanut shells at different magnifications are shown by Figure 4. Image of shells border (Figure 4(a)) shows an assembly of spherical particles which presents a great number of cavities. According to these images, peanut shells consist of an important porosity which could influence its thermal conductivity and water absorption. Shells inner (Figure 4(b)) consist of a weave of fine fiber which protects all the interior of shells from any external contact. Image of shells exterior (Figure 4(c)) shows a roughness surface which could well allow the adhesion of the earth matrix during the production of adobes. SEM of the film covering the interior (Figure 5) shows clearly the nature of this film. EDS analysis (Figure 5) of the thin film shows that it is composed essentially by $\mathrm{CaO}(62.44 \%), \mathrm{K}_{2} \mathrm{O}(24.86 \%)$ and of $\mathrm{MgO}(12.70 \%)$.

\subsection{Water Absorption of Unground Shells}

Water absorption of peanut shells is one of determining parameters for future use as reinforce of adobes. Absorption curve (Figure 6) shown that from 72 hours, the absorbed water around $198 \mathrm{wt} \%$ of test mass. This important capacity of peanut shells to absorb water could be an advantage to produce moisture regulating adobes. Water absorption of the peanut shells is greater than that of palm and sisal fibers [2] but similar to that of date fiber and is feebler than water absorption of barley straw and wood aggregates [2].

\subsection{Physico-Chemical Analyze of Shells Powder}

The density of peanut shell powder is $(1.46 \pm 0.01) \mathrm{g} / \mathrm{cm}^{3}$. This value is comparable to those of cotton, flax and sisal fiber which around $1.5 \mathrm{~g} / \mathrm{cm}^{3}$ [2] [13]. It is slightly higher than the density of jute fibers which is $1.37 \mathrm{~g} / \mathrm{cm}^{3}$ [2]. The moisture content of peanut shell powders $(6.26 \pm 0.12) \%$ is feebler than that of flax and cotton but approximatively equal to hemp moisture content [2]. 

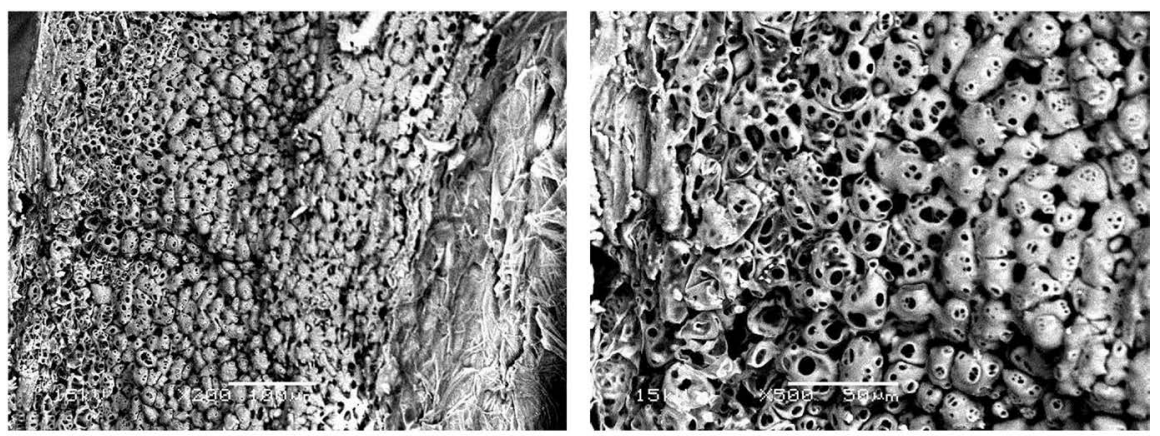

(a)
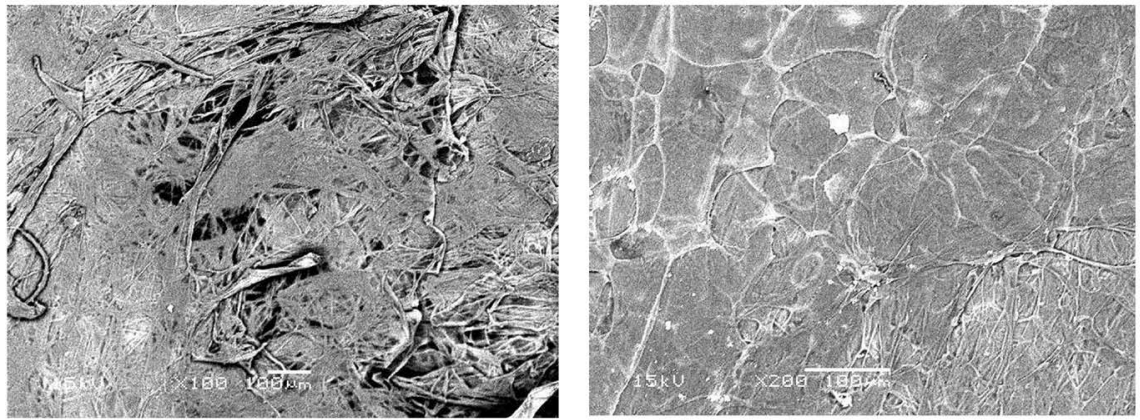

(b)
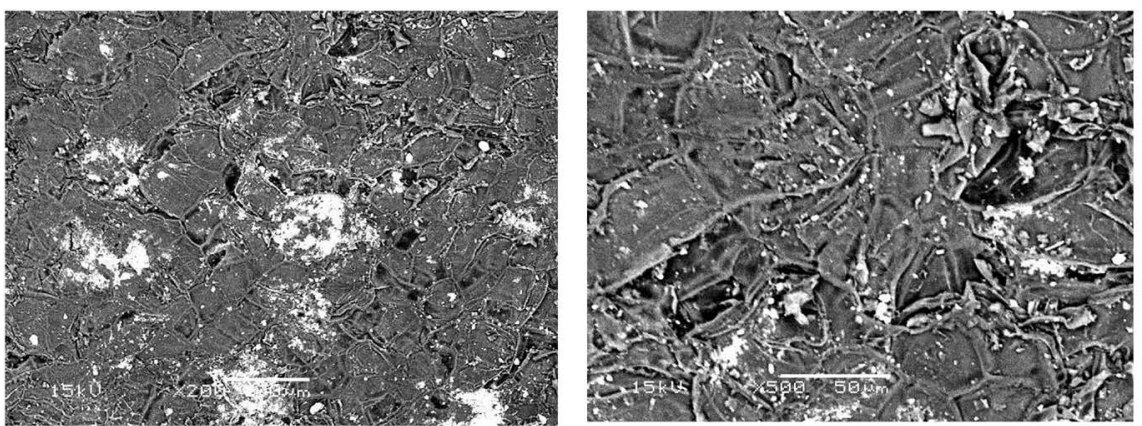

(c)

Figure 4. SEM image of peanut shells: (a) border; (b) inner surface; (c) exterior surface.
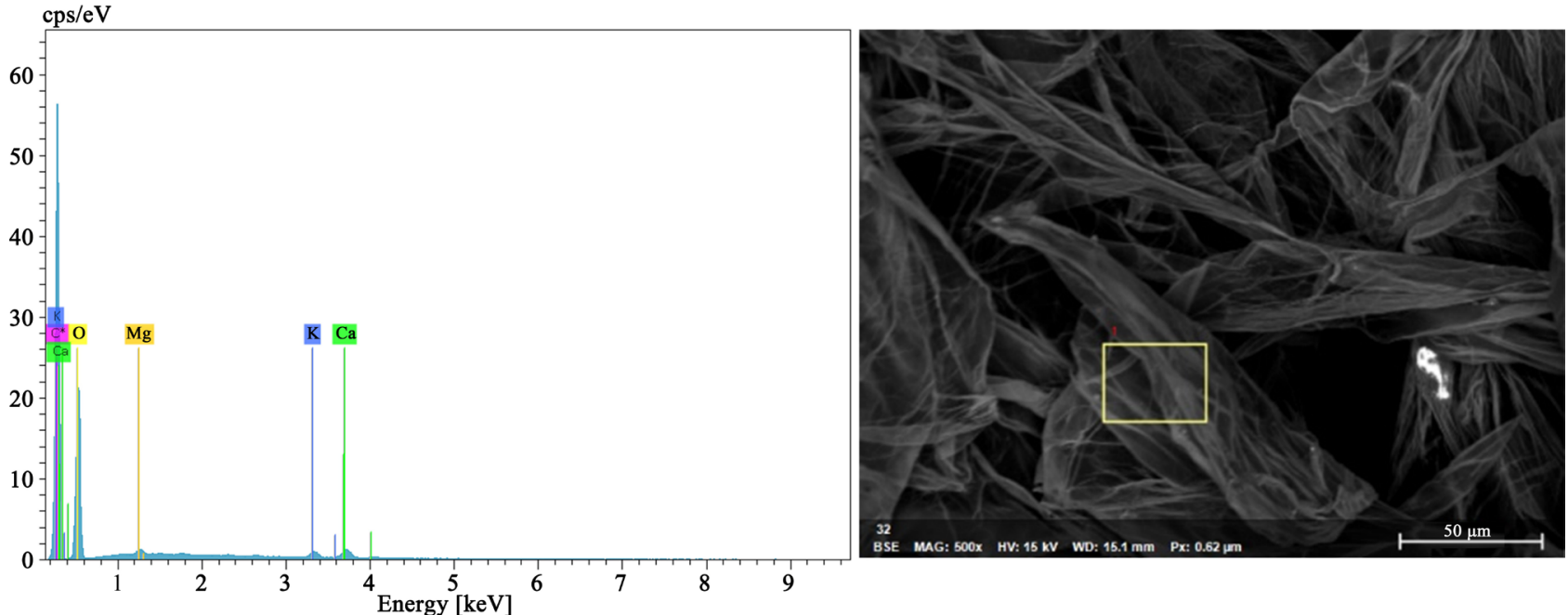

Figure 5. SEM image and EDS analysis of the film covering the inside of the shell. 
The particle size distribution of peanut shell powder $(\Phi<80 \mu \mathrm{m})$ is given by Figure 7. The powder was composed principally by one family of size respectively around $8 \mu \mathrm{m}$. At this family is associated with feeble proportion another family around $0.3 \mu \mathrm{m}$. Peanut shells powder is then composed by finer particle which can play a filler property and reduce then the adobe porosity.

The chemical composition of peanut shells is given in Table 1. Shells are composed mainly of organic matter as indicated by the high rate of loss on

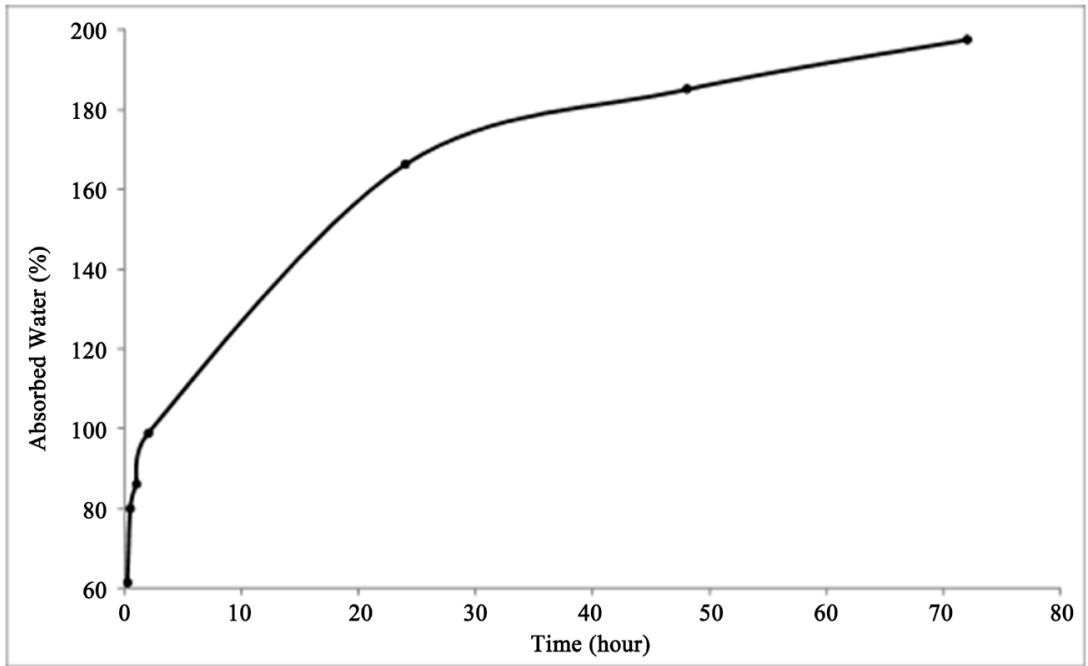

Figure 6. Water absorption of peanut shells.

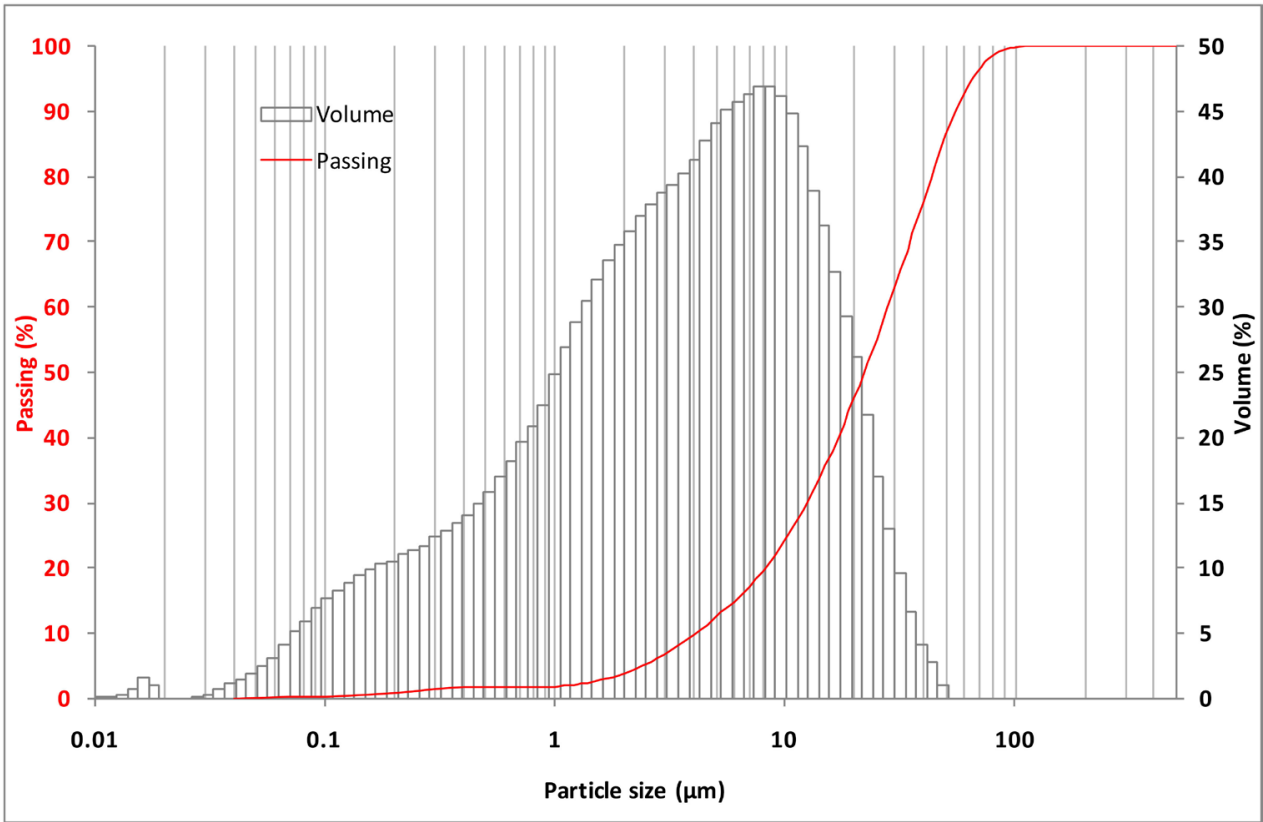

Figure 7. Particle size distribution of groundnut shell powder.

Table 1. Chemical composition of the groundnut shells powder.

\begin{tabular}{cccccccccc}
\hline Oxides & $\mathrm{SiO}_{2}$ & $\mathrm{Al}_{2} \mathrm{O}_{3}$ & $\mathrm{Fe}_{2} \mathrm{O}_{3}$ & $\mathrm{CaO}$ & $\mathrm{MgO}$ & $\mathrm{K}_{2} \mathrm{O}$ & $\mathrm{Na}_{2} \mathrm{O}$ & LOI & Total \\
$\mathbf{W t} \%$ & 5.92 & 2.41 & 6.05 & 2.1 & 0.3 & 1.55 & 0.11 & 80.56 & 99 \\
\hline
\end{tabular}


ignition (80.56\%). The few oxides in a relatively appreciable amount are iron oxide $(6.05 \%)$ and silica $(5.92 \%)$. Alumina, lime and potassium oxide are also present but in a lesser proportion.

\subsection{Mineralogical Analysis of Shells Powder}

FTIR spectra of peanut shell is reported in Figure 8. The stretching $\mathrm{O}-\mathrm{H}$ bond and $\mathrm{C}-\mathrm{H}$ bond respectively around 3340 and $2940 \mathrm{~cm}^{-1}$ were assigned to cellulose [14] [15]. The stretching $\mathrm{C}=\mathrm{O}$ and COO- respectively at 1749 and $1620 \mathrm{~cm}^{-1}$ were acetyl group in hemicelluloses or the ester and carboxylic acid in hemicelluloses, lignin or pectin. The C-O stretching at 1272 and $1035 \mathrm{~cm}^{-1}$ were attributable to aryl group in lignin [16]-[23].

X-ray diffraction pattern of peanut shells powder (Figure 9) correlated the

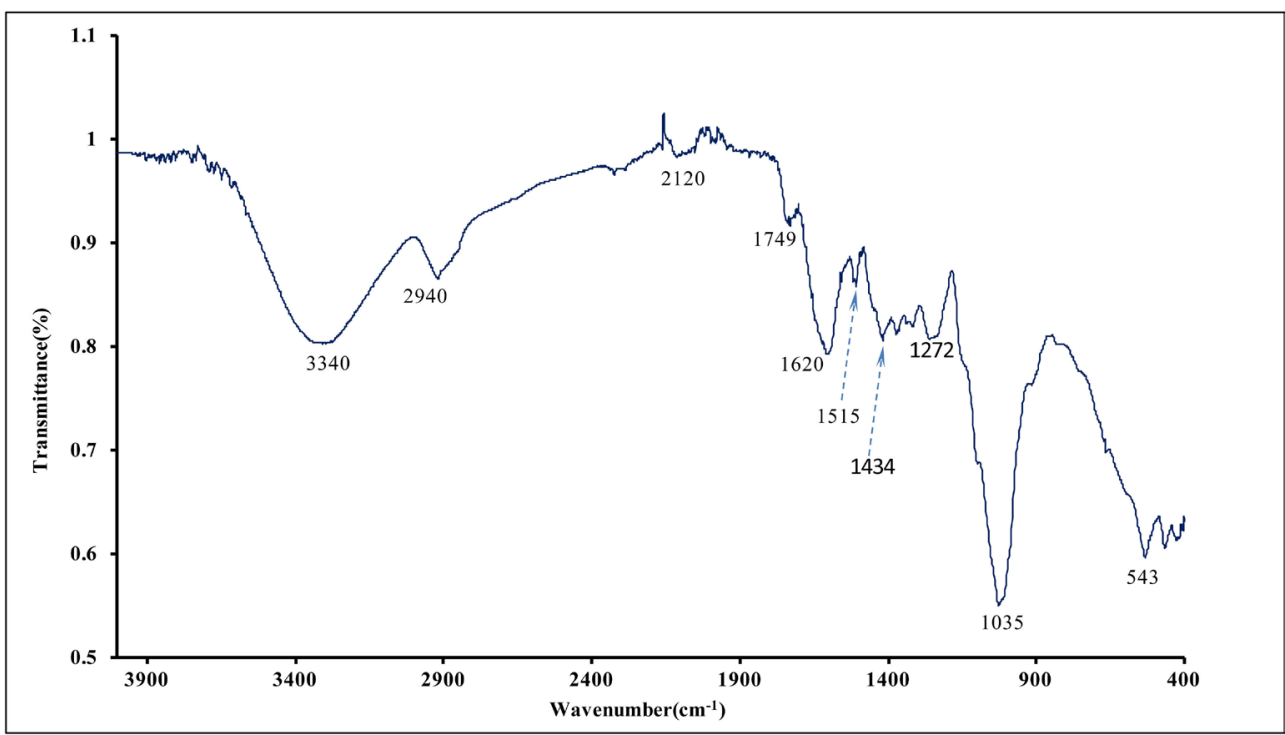

Figure 8. FTIR peanut shells powder.

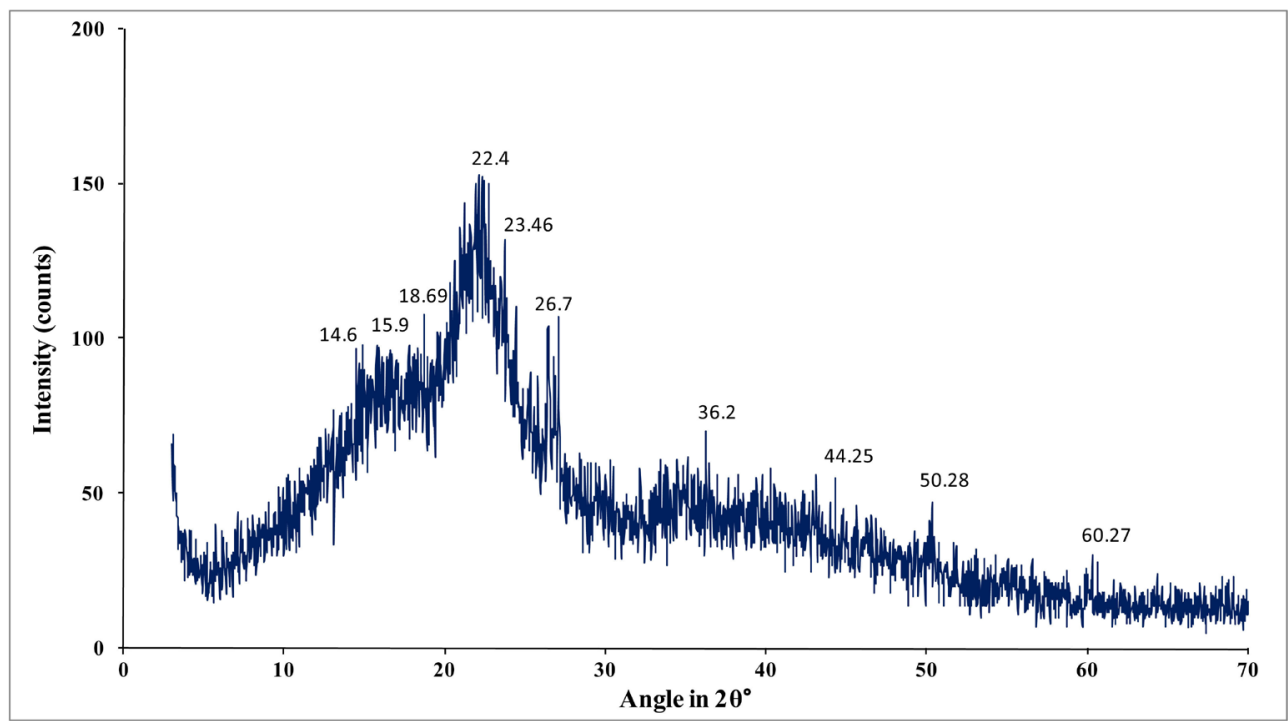

Figure 9. DRX peanut shells powder. 
infrared result. The disorder nature of X-ray diffraction pattern shows that the shell contains amorphous phase as hemicelluloses, lignin and pectin. The only detected crystalline phase is cellulose by its peaks at $14.6^{\circ}, 15.9^{\circ}, 22.7^{\circ}, 26.7^{\circ}$ and $36.2^{\circ} 2 \theta$. The crystallinity index of cellulose is estimated from the empirical formula of Segal [24]:

$$
I C=\frac{I_{200}-I_{A M}}{I_{200}}
$$

With $I_{200}$ the intensity of the diffraction peak at $2 \theta=25.8^{\circ}$ and $I_{A M}$ the intensity of the diffraction peak at $2 \theta=18.68$.

The determined index $28.47 \%$ is very low and indicates that shell cellulose is very disordered, which justifies the poor quality of X-ray diffraction pattern.

The DSC-TG curve of peanut shells (Figure 10) showed an endothermic and exothermic peak corresponding to transformation or pyrolysis of the shell's constituents. The first endothermic peak at $100^{\circ} \mathrm{C}$ with mass loss of $6 \%$ corresponds to departure of moisture water and could also correspond to the condensation of lignin [25]. The second endothermic peak between $200^{\circ} \mathrm{C}-300^{\circ} \mathrm{C}$ with mass loss of $18 \%$ corresponds to the degradation of hemicellulose. The third endothermic peak between $325^{\circ} \mathrm{C}$ and $370^{\circ} \mathrm{C}$ with a loss mass of $22 \%$ is attributable to the decomposition of the cellulose by depolymerization [26] [27] [28]. The first exothermic peak at $370^{\circ} \mathrm{C}$ with a loss mass of $4 \%$ corresponds to the release of the heat stored in the cellulose and which is restored after rupture of the structure. The broad exothermic peak centered at $400^{\circ} \mathrm{C}$ with a loss mass of $7 \%$ corresponds to the degradation of lignin.

Chemical composition (Table 2) showed that peanut shells are richer on cellulose (48 wt\%) followed by lignin (28 wt\%). Hemicellulose content in peanut shells

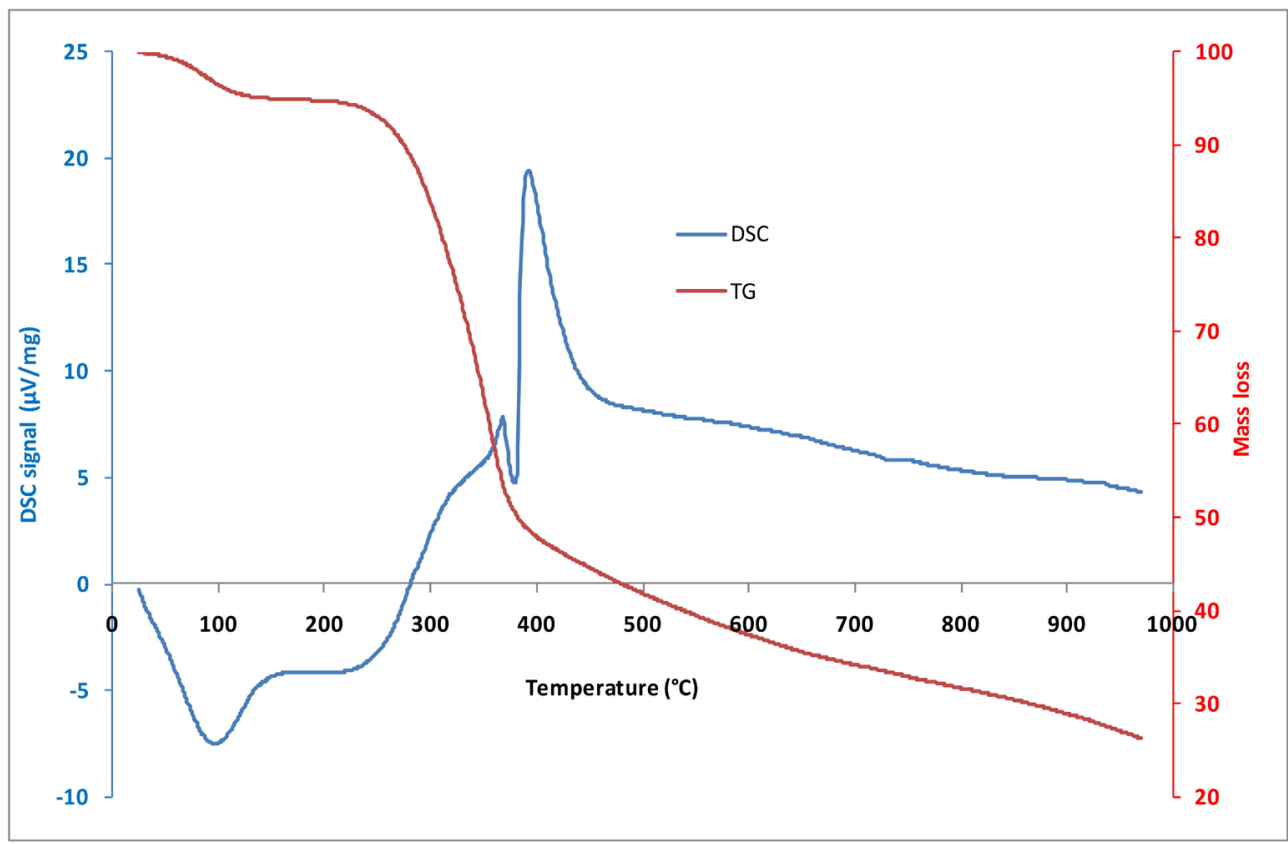

Figure 10. DSC-ATG peanut shells powder. 
is feeble comparable to kenaf, jute, flax fibers [2]. Cellulose and lignin content are in the same range for wood fiber. The other compound (21 wt\%) are probably proteins, minerals, pectin and tannins.

\subsection{Analyze of Extract from Peanut Shells}

UV-Visible spectrum of extract from peanut shells is given in Figure 11 and has composed of two bands. The first and widest, between 200 and $250 \mathrm{~nm}$ correspond to the electronic transitions $\pi==>\pi^{*}$ and is characteristic of the structures of the aromatic cycle of polyphenols (tannin). The second band between 275 and $325 \mathrm{~nm}$ corresponds to transition $\mathrm{n}==>\pi^{*}$ of the same polyphenols (tannins).

Tannin content is deduced from the standard curve. The obtained results for the both ways of extraction $(2670 \mu \mathrm{g} / \mathrm{g}$ and $2240 \mu \mathrm{g} / \mathrm{g})$ are relatively high compare to those found by B. Adhikari et al. [8] for six varieties of peanut from Korea which value is from 428.1 to $739.8 \mu \mathrm{g} / \mathrm{g}$. However, the extraction using shells ground then dried gives tannin slightly above the second way or the hulls are dried in the shade before being crushed.

\subsection{Thermal Conductivity of Peanut Shells}

Thermal conductivity of specimens made with peanut shells powder, determined at $24^{\circ} \mathrm{C}$, is $0.155 \pm 0.021 \mathrm{~W} \cdot \mathrm{m}^{-1} \cdot \mathrm{K}^{-1}$. This value is substantially equal to that found by J. C. Damfeu et al. [29] in 2016 which is $0.09 \mathrm{~W} \cdot \mathrm{m}^{-1} \cdot \mathrm{K}^{-1}$. The low thermal conductivity of peanut shells is an asset for their use in the stabilization of adobes. Indeed, addition of peanut shells to raw earth to produce adobes will

Table 2. Composition of peanut shells powder.

\begin{tabular}{ccccc}
\hline & Cellulose & Hemicellulose & Lignin & Others \\
\hline wt $\%$ & 42 & 3 & 28 & 27
\end{tabular}

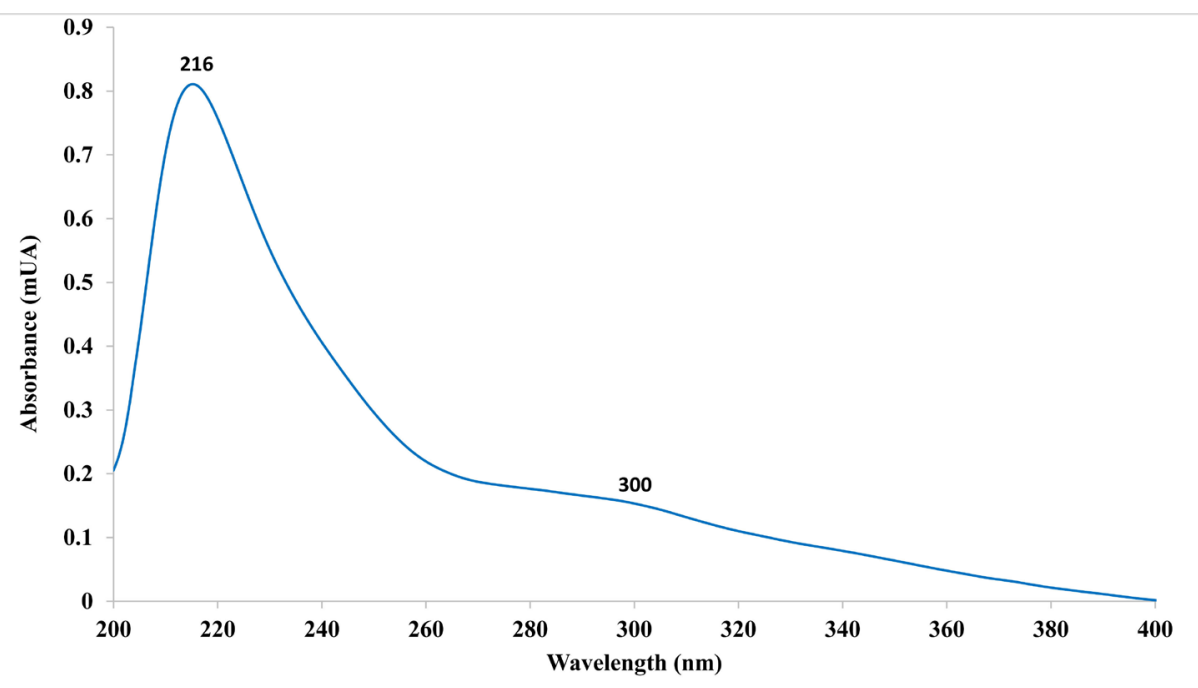

Figure 11. UV-Visible spectrum of peanut shell decoction. 
allow, to reduce the thermal conductivity of adobes and thus contribute to provide thermal comfort in houses that will be built.

\subsection{Capillary Absorption of Peanut Shells-Based Specimen}

Absorbed water versus contact time between the specimen and water is given in Figure 12. The sorptivity coefficient of specimen deduce by the equation $(\mathrm{s}=$ $0.50 \mathrm{~kg} / \mathrm{m}^{2} \cdot \mathrm{s}^{-1 / 2}$ ) is very feeble and corroborates the feeble height (around $3 \mathrm{~cm}$ ) of the water mounted by capillarity on the brick as shown in Figure 3.

Water absorption by capillary depends principally into open porosity of the specimen. The water absorption by capillary of the brick from the peanut shell powder is low and indicates a material with low open porosity. The material is dense, and this densification is the probable formation of sticky gel and hydrogen bonds between the organic molecular contain in the peanut shell.

\section{Discussion}

Peanut shells elementary chemical composition indicates the presence of iron, aluminum, lime, silica and potassium. Any toxic elements to human health do not revel so as to compromise the use of shells in the construction of habitats. Density of shells $\left(1.46 \mathrm{~g} / \mathrm{cm}^{3}\right)$ is in the same order of those of vegetable materials used in the production of earth bricks to improve their mechanical strength or their dimensional stability and to reduce their thermal conductivity. According to research data, density of fibers (jute, kenaf, flax, hemp) is between 1.04 and $1.5 \mathrm{~g} / \mathrm{cm}^{3}$; agricultural residues (cassava, cotton, tea, tobacco, grass) between 0.5 and $1.35 \mathrm{~g} / \mathrm{cm}^{3}$ and straws (wheat, barley, beer) between 0.86 and $2.05 \mathrm{~g} / \mathrm{cm}^{3}$.

The size of peanut shells between 1 and $4 \mathrm{~cm}$ should not be a handicap to its use in earth bricks. The dimensions of fibers $(0.5-8.5 \mathrm{~cm})$, agricultural residues $(0.01-5 \mathrm{~cm})$ and straws $(1-30 \mathrm{~cm})$ used in the reinforcement of the mechanical

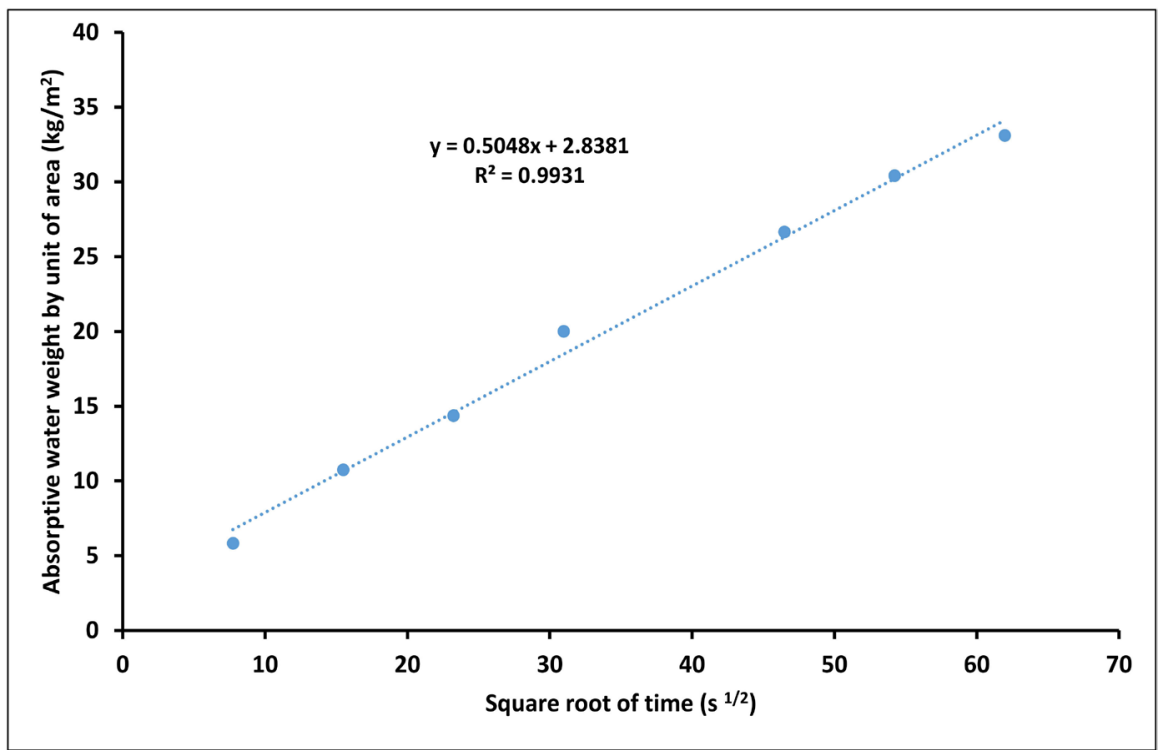

Figure 12. Capillary water absorption by specimen. 
strengths of adobes indicates that the size of peanut shells is appropriate for their use as reinforce. So, shells powder is composed of finer particles which could play a filler role in the adobe matrix and reduce considerably its porosity.

Microstructure of shells indicates a very porous material that explains its high-water absorption and low thermal conductivity. The examination of shells inner shows that the shells are the compilation of microfiber. Roughness of external surface offers adhesion possibilities to raw earth during the production of brick. Shells are composed mainly of cellulose, hemicellulose and lignin as found in most plant materials.

In solution, peanut shells release polyphenolic macromolecules which are able to react by complexing mechanisms with some ions like iron and participate in the consolidation-densification of adobe.

The water absorption of shells (198\% of their mass) is comparable to that of fibers $(80 \%-307 \%)$ and agricultural residues (97\% - 203\%). It is lower than the absorption of straw $(280 \%-600 \%)$. The significant absorption of water of shells improves their property of humidity regulation inside the houses.

\section{Conclusion}

Peanut shells are agricultural waste that has all the properties of plant materials used in the stabilization of earth bricks. They have a low conductivity and a high-water absorption that can validly justify their use in the production of ecological habitats requiring less energy to achieve thermal comfort in the interior. The release of polyphenol macromolecules from the shells in an aqueous medium is an asset to the stabilization of adobes. In this case, the shells can be used to amend earth bricks.

\section{Conflicts of Interest}

The authors declare no conflicts of interest regarding the publication of this paper.

\section{References}

[1] Jové-Sandoval, F., Barbero-Barrera, M.M. and Nelson, F.M. (2018) Assessment of the Mechanical Performance of Three Varieties of Pine Needles as Natural Reinforcement of Adobe. Construction and Building Materials, 187, 205-213. https://doi.org/10.1016/j.conbuildmat.2018.07.187

[2] Laborel-Préneron, A., Aubert, J.E., Magniont, C., Tribout, C. and Bertron, A. (2016) Plant Aggregates and Fibers in Earth Construction Materials: A Review. Construction and Building Materials, 111, 719-734. https://doi.org/10.1016/j.conbuildmat.2016.02.119

[3] Mesbah, A., Morel, J.C., Walker, P. and Ghavami, K. (2004) Development of a Direct Tensile Test for Compacted Earth Blocks Reinforced with Natural Fibers. Journal of Materials in Civil Engineering, 16, 95-98. https://doi.org/10.1061/(ASCE)0899-1561(2004)16:1(95)

[4] Ouedraogo, M., Dao, K., Millogo, Y., Aubert, J.E., Messan, A., Seynou, M., Zerbo, L. and Gomina, M. (2019) Physical, Thermal and Mechanical Properties of Adobes 
Stabilized with Fonio (Digitaria exilis) Straw. Journal of Building Engineering, 23, 250-258. https://doi.org/10.1016/j.jobe.2019.02.005

[5] Sayyed Mahdi, H., Mohammad, S., Sayyed Mahdi, A. and Ali, Z. (2012) A Simple Review of Soil Reinforcement by Using Natural and Synthetic Fibers. Construction and Building Materials, 30, 100-116.

https://doi.org/10.1016/j.conbuildmat.2011.11.045

[6] Yetgin, Ş., Çavdar, Ö. and Çavdar, A.B. (2008) The Effects of the Fiber Contents on the Mechanic Properties of the Adobes. Construction and Building Materials, 22, 222-227. https://doi.org/10.1016/j.conbuildmat.2006.08.022

[7] http://perspective.usherbrooke.ca/bilan/tend/BFA/fr/RS.NUT.PROD.PP.MT.html

[8] Bishnu, A., Dhungana, S.K., Ali, M.W., Adhikari, A., Kim, I.-D. and Shin, D.-H. (2019) Antioxidant Activities, Polyphenol, Flavonoid, and Amino Acid Contents in Peanut Shell. Journal of the Saudi Society of Agricultural Sciences, 18, 437-442. https://doi.org/10.1016/j.jssas.2018.02.004

[9] Rosales-Martínez P., Arellano-Cárdenas, S., Dorantes-Álvarez, L., García-Ochoa, F. and López-Cortez, M.S. (2014) Comparison between Antioxidant Activities of Phenolic Extracts from Mexican Peanuts, Peanuts Skins, Nuts and Pistachios. Journal of the Mexican Chemical Society, 58, 185-193.

[10] Juarez, C., Fajardo, G. and Valdez, P. (2009) Caracterisation Microstructurale des Fibres Naturelles pour des Materiaux Composites a Base de Ciment. Canadian Journal of Civil Engineering, 36, 449-462. https://doi.org/10.1139/L09-009

[11] Magniont, C. (2010) Contribution à la Formulation et à la Caractérisation D'un Écomatériau de Construction à Base D'agroressources. These de L'INSA de Toulouse.

[12] Singleton, V.L., Orthofer, R. and Lamuela-Raventos, R.M. (1999) Analysis of Total Phenols and Other Oxidation Substrate and Antioxidant by Means Folin-Ciocalteu Reagent. Methods in Enzymology, 299, 152-178. https://doi.org/10.1016/S0076-6879(99)99017-1

[13] Halil, M.A. and Paki, T. (2008) Cotton and Limestone Powder Wastes as Brick Material. Construction and Building Materials, 22, 1074-1080. https://doi.org/10.1016/j.conbuildmat.2007.03.006

[14] Shanshan, H., Chad, A.U., Haoran, W. and Xinnan, W. (2013) Chemical and Mechanical Properties Studies of Chinese Linen Flax and Its Composites. Polymer Composites, 21, 275-285.

[15] Kondo, T. and Sawatari, C. (1996) A Fourier Transform Infra-Red Spectroscopic Analysis of the Character of Hydrogen Bonds in Amorphous Cellulose. Polymer, 37, 393-399. https://doi.org/10.1016/0032-3861(96)82908-9

[16] Jonoobi, M., Harun, J., Tahir, P.M., Shakeri, A., Saifulazry, S. and Makinejad, M.D. (2011) Physicochemical Characterization of Pulp and Nanofibers from Kenaf Stem. Materials Letters, 65, 1098-1100. https://doi.org/10.1016/j.matlet.2010.08.054

[17] Sedan, D. (2007) Étude des Interactions Physico-Chimiques aux Interfaces Fibres de Chanvre/Ciment: Influence sur les Propriétés Mécaniques du Composite. Thèse de Doctorat, Université de Limoges, Limoges,

[18] Troedec, M.L., Sedan, D., Peyratout, C., Bonnet, J.P., Smith, A. and Guinebretiere, R. (2008) Influence of Various Chemical Treatments on the Composition and Structure of Hemp Fibres. Composites Part A: Applied Science and Manufacturing, 39, 514-522. https://doi.org/10.1016/j.compositesa.2007.12.001

[19] Sain, M. and Panthapulakkal, S. (2006) Bioprocess Preparation of Wheat Straw Fibers and Their Characterization. Industrial Crops and Products, 23, 1-8. 
https://doi.org/10.1016/j.indcrop.2005.01.006

[20] Fernandez, K. and Agosin, E. (2007) Quantitative Analysis of Red Wine Tannins Using Fourier Transform Mid-Infrared Spectrometry. Journal of Agricultural and Food Chemistry, 55, 7294-7300. https://doi.org/10.1021/jf071193d

[21] Blanchart, P., Dembelé, A., Dembelé, C., Plea, M., Bergstrom, L., Garnet, R., Sol, V., Gloaguen, V., Degot, M. and Krauss, P. (2010) Mechanism of Traditional Bogolan Dyeing Technique with Clay on Cotton Fabric. Applied Clay Science, 50, 455-460. https://doi.org/10.1016/j.clay.2010.08.029

[22] Alemdar, A. and Sain, M. (2008) Isolation and Characterization of Nanofibers from Agricultural Residues-Wheat Straw and Soy Hulls. Bioresource Technology, 99, 1664-1671. https://doi.org/10.1016/j.biortech.2007.04.029

[23] Khallouki, F., Haubner, R., Hull, W.E., Erben, G., Spiegelhalder, B., Bartsch, H. and Owen, R.W.I. (2007) Isolation, Purification and Identification of Ellagic Acid Derivatives, Catechins, and Procyanidins from the Root Bark of Anisophyllea dichostyla, R. Br. Food and Chemical Toxicology, 45, 472-485. https://doi.org/10.1016/j.fct.2006.09.011

[24] Segal, L., Creely, J.J., Martin Jr., A.E. and Conrad, C.M. (1959) An Empirical Method for Estimating the Degree of Crystallinity of Native Cellulose Using the X-Ray Diffractometer. Textile Research Journal, 29, 786-794.

https://doi.org/10.1177/004051755902901003

[25] Akita, K. and Kase, M. (1967) Determination of Kinetic Parameters for Pyrolysis of Cellulose and Cellulose Treated with Ammonium Phosphate by Differential Thermal Analysis and thermal Analysis and Thermal Gravimetric Analysis. Journal of Polymer Science Part A-1: Polymer Chemistry, 5, 833-848. https://doi.org/10.1002/pol.1967.150050411

[26] Fisher, T., Hajaligol, M., Waymack, B. and Kellogg, D. (2002) Pyrolisis Behavior and Kinetics of Biomass Derived Materials. Journal of Analytical and Applied Pyrolysis, 62, 331-349. https://doi.org/10.1016/S0165-2370(01)00129-2

[27] Cagnon, B., Py, X., Guillot, A., Stoeckli, F. and Chambat, G. (2009) Contributions of Hemicellulose, Cellulose and Lignin to the Mass and the Porous Properties of Chars and Steam Activated Carbons from Various Lignocellulosic Percursors. Bioresource Technology, 100, 292-298. https://doi.org/10.1016/j.biortech.2008.06.009

[28] Ouajai, S. and Shanks, R.A. (2009) Composition, Structure and Thermal Degradation of Hemp Cellulose after Chemical Treatments. Polymer Degradation and Stability, 89, 327-335. https://doi.org/10.1016/j.polymdegradstab.2005.01.016

[29] Damfeu, J.C., Meukam, P. and Jannot, Y. (2016) Modeling and Measuring of the Thermal Properties of Insulating Vegetable Fibers by the Asymmetrical Hot Plate Method and the Radial Flux Method: Kapok, Coconut, Peanut Shell Fiber and Rattan. Thermochimica Acta, 630, 64-77. https://doi.org/10.1016/j.tca.2016.02.007 